\title{
PLYOMETRICS: MENINGKATKAN POWER OTOT TUNGKAI DAN UNDER SHOOT ATLET BOLA BASKET
}

\author{
Rachlai Eko Arisetiawan "1, Andi Fepriyanto², Nugroho Agung Supriyanto ${ }^{3}$ \\ STKIP PGRI Sumenep, Indonesia ${ }^{1,2,3}$

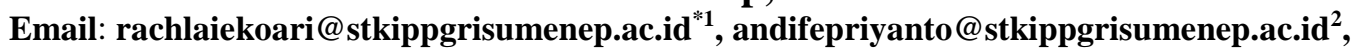 \\ agungnugroho@stkippgrisumenep.ac.id ${ }^{3}$
}

\author{
Received: 10 November 2019; Accepted 30 May 2020; Published 15 June 2020
}

Ed 2020; 5(1): 76-83

\begin{abstract}
ABSTRAK
Tujuan dari penelitian ini adalah untuk mengetahui pengaruh latihan plyometric single leg jump dan depth jump terhadap daya ledak dan under shoot. Penelitian ini menggunakan 18 subjek pemain bola basket dengan menggunakan metode purposive sampling. Hasil penelitian menunjukkan adanya pengaruh yang signifikan antara sebelum dan sesudah latihan pada kelompok I plyometric single leg jump terhadap peningkatan power dan hasil Under shoot, pada kelompok II depth jump adalah adanya pengaruh yang signifikan antara sebelum dan sesudah latihan terhadap peningkatan power dan under shoot, sedangkan pada kelompok III kontrol tidak ada pengaruh yang signifikan terhadap peningkatan power dan under shoot. Dapat kesimpulan pada kelompok I plyometric single leg jump dan kelompok II depth jump kekuatan daya ledak dan under shoot sama-sama memberikan pengaruh yang signifikan pada atlet bola basket.
\end{abstract}

Kata Kunci: Plyometric; Single Leg Jump; Depth Jump; Power; Under Shoot; Bola Basket.

\section{PLYOMETRICS: TO IMPROVE POWER OF MUSCLE AND UNDER SHOOT OF BASKETBALL ATHLETE}

\section{ABSTRACT}

The aim of this study was to determine the effect of plyometric exercises in single leg jump and depth on explosive power and under shoot. This study used 18 basketball players. The results showed a significant influence between before and after training in group I plyometric single leg jump to increase power and Under shoot results, in group II depth jump was a significant effect between before and after training on increasing power and under shoot, whereas in group III the control had no significant effect on increasing power and under shooting. It can be concluded that the group I plyometric single leg jump and group II depth jump explosive power and under shoot both have a significant influence on basketball athletes.

Keywords: Plyometric; Single Leg Jump; Depth Jump; Power; Under Shoot; Basketball.

Copyright (C) 2020, Journal Sport Area

DOI: https://doi.org/10.25299/sportarea.2020.vol5(1).4059

How To Cite: Arisetiawan, R. E., Febriyanto, A., \& Supriyanto, A. N. (2020). Plyometrics: Meningkatkan Power Otot Tungkai dan Under Shoot Atlet Bola Basket. Journal Sport Area, 5(1), 76-83.

\section{PENDAHULUAN}

Bola basket merupakan salah satu cabang olahraga beregu di Indonesia. Bola basket berisikan 5 orang dalam satu tim yang mempunyai tugas dan peranan masing-masing dalam permainan untuk mendapatkan sebuah kemenangan. Bola basket adalah cabang olahraga yang mengharuskan tim mencetak poin sebanyak-banyak dalam jangka waktu tertentu (Wanena, 2018). Bola basket memiliki beberapa teknik dasar bermain, seperti yang dinyatakan Wanena (2018) teknik dasar dalam bola basket terdiri dari shooting, 
dribbling, defend, pivot dan lain-lain sebagainya. Butuh penguasaan teknik dasar tersebut oleh setiap pemain dalam sebuah tim. Asadi (2013) menyebutkan bahwa teknik dasar bola basket harus dikuasai oleh seluruh anggota tim bola basket agar bisa berprestasi. Sedangkan komponen fisik yang harus dimilki oleh pemain bola basket adalah agilty, kekuatan, daya tahan, koordinasi, keseimbangan, kecepatan dan daya ledak (Bal, Kaur, \& Singh, 2011).

Cara untuk mendapatkan poin adalah dengan memasukkan bola ke dalam ring. Kebanyakan untuk mendapatkan poin pemain harus melompat untuk melakukan lay up, jump shoot atau slamdunk. Hal ini menunjukkan pemain harus mempunyai kemampuan melompat yang baik sehingga menghasilkan performa yang maksimal. Lompatan dalam bola basket sangat diperlukan karena berhubungan dengan beberapa teknik dalam permainannya seperti lay up, block, jump shoot, slamdunk dan rebound. Lompatan sangat berhubungan erat dengan daya ledak. Beberapa hal yang mempengaruhi daya ledak seseorang adalah sistem energi anaerobik atlet, jika energi anaerobik tinggi maka lompatan juga akan semakin tinggi (Adibpour, Bakht, \& Behpour, 2012).

Daya ledak merupakan komponen yang yang berhubungan dengan lompatan dan perlu ditingkatkan bagi pemain bola basket agar memiliki performa yang bagus, seperti yang dinyatakan (Asadi, 2013) untuk meningkatkan daya ledak dan kegesitan kinerja pemain bola basket pelatih dan pemain bola basket yang menggunakan metode pelatihan ini selama fase kompetitif yaitu plyometric. Daya ledak diperlukan oleh pemain untuk berganti posisi dari menyerang ke bertahan. Hal ini dikarenakan ada waktu setiap tim untuk menyerang lawan.

Latihan plyometric mulai terkenal dan berkembang dalam beberapa waktu belakangan ini. Plyometric merupakan latihan yang bisa digunakan untuk meningkatkan kemampuan lompat dan daya ledak otot pemain (Jaya, Tirtayasa, Muliarta, Adiputra, Purnawati, \& Griadhi., 2018). Hidayat, Saichhudin, dan Kinanti (2017) juga menyatakan bahwa terdapat pengaruh pemberian latihan plyometric jump to box terhadap peningkatan power otot tungkai. Hasil penelitian sebelumnya juga menyatakan bahwa latihan plyometric memiliki efek positif untuk meningkatkan daya dan kegesitan kinerja pemain bola basket pria muda (Asadi, 2013), sedangkan (Adibpour et al., 2012), menunjukkan bahwa latihan plyometric ini juga dapat membangun otot-otot kaki dan meningkatkan daya ledak kaki. Oleh karena itu, aplikasi latihan gabungan untuk olahraga lompat disarankan. Latihan plyometric merupakan latihan yang mengutamakan pengulangan kontraksi otot sehingga bisa bertambah meningkat (Bal et al., 2011). Hal ini sesuai dengan kebutuhan dalam bola basket yang memerlukan kemampuan lompatan yang baik untuk bertahan maupun menyerang.

Urgensi pada penelitian ini terfokus pada aspek performa atlet yang belum pernah dilakukan pelatihan plyometric serta pengukuran atau penelitian secara tertulis untuk mengetahui kondisi fisik atlet dalam persiapan menghadapi kejuaran bola basket yang diikuti apalagi dalam mempersiapkan pada kejuaraan Pra PORPROV di tahun 2019. Hal ini sesuai dengan hasil wawancara dengan pelatih Bola Basket Pra PORPOV yaitu Bapak Priambodo bahwa belum pernah dilakukan latihan plyometric untuk meningkatkan otot tungkai, sehingga penulis mencoba bekerjasama dengan Pengkab PERBASI Sumenep dalam kesempatan ini bisa mengevalusi kondisi fisik atlet tim bola basket Sumenep dalam persiapan menghadapi Pra PORPROV di tahun 2019. Sehingga dalam rangka meningkatkan prestasi olahraga bola basket Kabupaten Sumenep peneliti mengadakan penelitian pengaruh plyometric single leg depth jump dan plyometric depth 
jump terhadap power otot tungkai dan under shoot pada atlet bola basket. Tujuan penelitian ini yaitu meningkatkan power otot tungkai dan hasil underbasket shoot digunakan dua model pelatihan plyometric yaitu depth jumps dan single leg depth jump.

\section{METODE PENELITIAN}

Penelitian menggunakan jenis penelitian kuantitatif dengan metode eksperimen. Desain penelitian ini menggunakan one group pretest- posttest design (Maksum, 2012). Populasi penelitian ini adalah atlet bola basket putra tim Sumenep yang akan mengikuti seleksi Pra PORPROV tahun 2019 sebanyak 18 orang. Subjek akan dibagi menjadi 3 kelompok yang terdiri dari 6 orang tiap kelompok. Terdiri dari kelompok I adalah kelompok yang mendapatkan perlakuan plyometric single leg depth jump. Kelompok II adalah kelompok yang mendapatkan perlakuan plyometric depth jump. Kelompok III adalah kelompok kontrol tanpa adanya perlakuan. Pemilihan subjek masuk pada kategori kelompok dipilih secara acak dengan cara diundi.

Teknik pengumpulan data dimulai dari menyampaikan tujuan dan maksud penelitian kepada pelatih dan subjek penelitian. Setelah itu, subjek diminta untuk mengisi informed consent sebagai tanda bersedia mengikuti kegiatan penelitian ini sampai selesai. Setiap subjek akan diambil data pada variabel terikat penelitian ini yaitu daya ledak otot (power) dan kemampuan under shoot terlebih dahulu sebagai data awal dan akhir setelah pemberian perlakuan pada masing-masing kelompok tersebut. Alat atau instrumen yang digunakan untuk mengukur daya ledak adalah jump $d f$ sementara untuk instrumen yang dipakai mengukur kemampuan under shoot adalah tes under shoot (Nurhasan, 2000). Kemudian kelompok yang diberikan perlakuan akan mulai dijelaskan tentang plyometric sesuai dengan kelompoknya. Perlakuan plyometric dilakukan selama 6 minggu dengan 18 kali pertemuan. Pada saat pelaksanaan setiap pertemuan setiap atlet melakukan pelatihan selama 60 menit yang terdiri dari 10 menit pemanasan, 40 menit latihan inti, dan 10 menit pendinginan.

Latihan plyometric dilakukan di atas box yang berukuran $30.48 \mathrm{~cm}$. Subjek berdiri dekat dengan box, kemudian melangkah ke box tersebut dan turun satu kaki (untuk single leg jump) dan dua kaki (untuk depth jump) kemudian melompat lagi setinggitinggi dengan menyentuh tanah sesingat-singkatnya (Chu \& Meyer, 2013). Analisa data hasil penelitian menggunakan metode statistika uji t.

\section{HASIL DAN PEMBAHASAN}

Sebelum menguji hipotesis pada penelitian ini akan dihitung uji prasyarat data meliputi uji normalitas data dan uji homogenitas data. Seperti pembahasan di bawah ini:

\section{Uji Normalitas}

Hasil uji normalitas menunjukkan apakah data memiliki distribusi normal atau tidak dapat dilihat pada tabel 1 .

Tabel 1. Hasil Uji Normalitas dengan Taraf Signifikan $\alpha=0.05$

\begin{tabular}{ccccc}
\hline \multirow{2}{*}{ Kelompok } & \multicolumn{2}{c}{ Power $\left(\mathrm{kg} \cdot \mathrm{m}^{2} \cdot \mathrm{s}^{-3}\right)$} & \multicolumn{2}{c}{ Under Shoot (Poin) } \\
\cline { 2 - 5 } & Pre Test & Post Test & Pre Test & Post Test \\
\hline $\begin{array}{c}\text { Kolmogorov- } \\
\text { Smirnov } Z\end{array}$ & 0.886 & 0.649 & 0.992 & 0.748 \\
\hline
\end{tabular}




\begin{tabular}{ccccc}
\hline \multirow{2}{*}{ Kelompok } & \multicolumn{2}{c}{ Power $\left(\mathrm{kg} \cdot \mathrm{m}^{2} \cdot \mathbf{s}^{-3}\right)$} & \multicolumn{2}{c}{ Under Shoot (Poin) } \\
\cline { 2 - 5 } & Pre Test & Post Test & Pre Test & Post Test \\
\hline Signifikansi & 0.05 & 0.05 & 0.05 & 0.05 \\
\hline Keterangan & Normal & Normal & Normal & Normal \\
\hline
\end{tabular}

Dari tabel 1 di atas menunjukkan bahwa hasil uji normalitas menggunakan Kolmogorov-Smirnov $Z$ menunjukkan hasil yang signifikan nilai yang diperoleh baik pre-test maupun post-test semuanya lebih besar dari $\alpha 0.05$.

\section{Uji Homogenitas}

Hasil uji homogenitas digunakan untuk mengetahui apakah data homogen atau tidak dapat dilihat pada tabel 2.

Tabel 2. Hasil Uji Homogenitas dengan Taraf Signifikan $\alpha=0.05$

\begin{tabular}{ccccc}
\hline \multirow{2}{*}{ Kelompok } & \multicolumn{2}{c}{ Power $\left(\mathbf{k g} \cdot \mathbf{m}^{2} \cdot \mathbf{s}^{-3}\right)$} & \multicolumn{2}{c}{ Under shoot (poin) } \\
\cline { 2 - 5 } & Pre Test & Post Test & Pre Test & Post Test \\
\hline $\begin{array}{c}\text { Homogenity of } \\
\text { Variance }\end{array}$ & 0.087 & 0.379 & 0.413 & 0.216 \\
\hline Signifikansi & 0.05 & 0.05 & 0.05 & 0.05 \\
\hline Keterangan & Homogen & Homogen & Homogen & Homogen \\
\hline
\end{tabular}

Dari tabel 2 di atas menunjukkan hasil uji homogenitas pre-test maupun post-test di atas menunjukkan nilai yang lebih besar dibandingkan $\alpha 0.05$.

\section{Uji Hipotesis}

Hasil penelitian membuktikan bahwa bentuk latihan plyometric single leg jump dan plyometric depth jump menghasilkan peningkatan yang siginifikan khususnya pada bagian power tungkai dan kemampuan under shoot. Kelompok kontrol justru mengalami penurunan pada power otot tungkai dan mengalami peningkatan pada kemampuan under shoot seperti yang terlihat pada tabel 3 .

Tabel 3. Power dan Under Shoot Sebelum dan Setelah Latihan Plyometrik

\begin{tabular}{ccccc}
\hline \multirow{2}{*}{ Kelompok } & \multicolumn{2}{c}{ Power $\left(\mathbf{k g} \cdot \mathbf{m}^{2} \cdot \mathbf{s}^{-3}\right)$} & \multicolumn{2}{c}{ Under shoot (poin) } \\
\cline { 2 - 5 } & Pre Test & Post Test & Pre Test & Post Test \\
\hline Single Leg Jump & $251,36 \pm 12,92$ & $273,22 \pm 18,48^{*}$ & $5,67 \pm 0,75$ & $8,17 \pm 0,69^{*}$ \\
\hline Depth Jump & $246,23 \pm 14,90$ & $268,30 \pm 14,85^{*}$ & $5,83 \pm 1,57$ & $8,17 \pm 1,57^{*}$ \\
\hline Kontrol & $239,02 \pm 6,31$ & $234,66 \pm 6,52$ & $4,67 \pm 0,75$ & $5,17 \pm 0,69$ \\
\hline
\end{tabular}

*) Berbeda Secara Siginifikan Antara Pre Test dan Post Test $(p<0.05)$ 


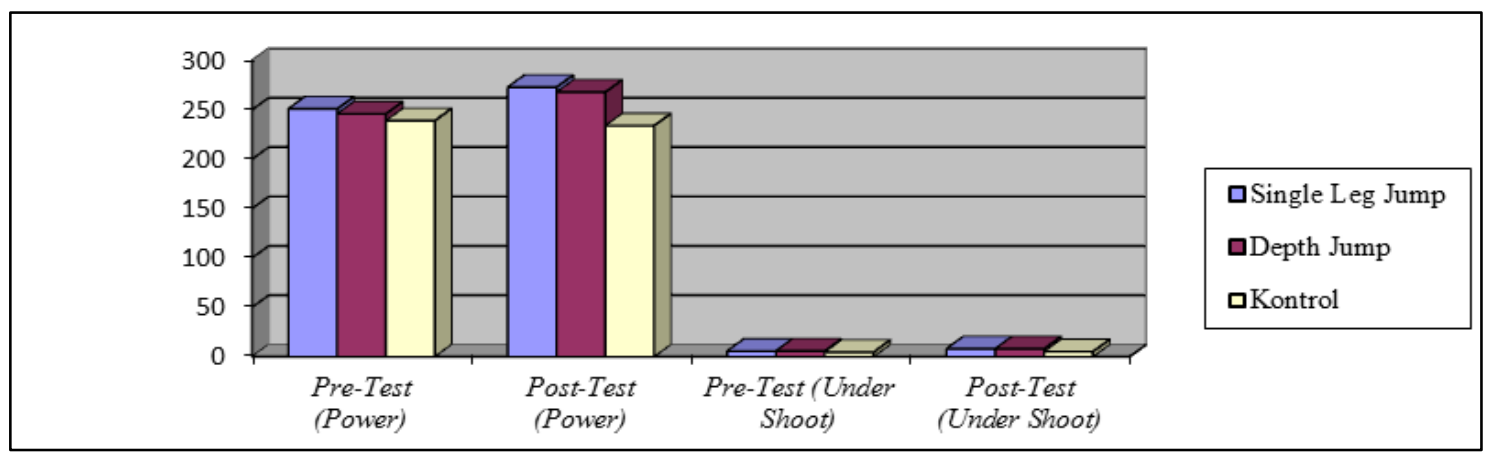

Grafik 1. Hasil Analisis Kelompok Eksperimen Power, Under Shoot dan Kelompok Kontrol

Berdasarkan grafik di atas dapat dilihat bahwa penelitian ini menunjukkan hasil post-test lebih tinggi dari hasil pre-test baik pada power maupun under shoot begitu juga tampak pada kelompok eksperimen single leg jump dan depth jump lebih tinggi dari pada kelompok kontrol sehingga menunjukkan latihan plyometric single leg jump dan depth jump dari grafik di atas menunjukkan adanya peningkatan yang signifikan. Kelompok eksperimen single leg jump menunjukkan grafik tertinggi dibandingkan pada kelompok eksperimen depth jump dan kelompok kontrol. Sehingga tujuan dari penelitian ini tercapai.

Tujuan penelitian ini untuk meningkatkan power otot tungkai dan hasil underbasket shoot digunakan dua model pelatihan plyometric yaitu depth jumps dan single leg depth jump. Pemilihan kedua model pelatihan tersebut didasari pertimbangan bahwa kedua model tersebut dalam pelaksanaannya banyak menggunakan kelompok-kelompok otot yang digunakan saat atlet bola basket melaksanakan under basket shoot.

Kemampuan daya ledak seseorang berhubungan dengan kemampuan perpindahan dan lompatan seseorang (Rajan \& Pushparajan, 2010). Beberapa faktor yang mempengaruhi daya ledak seseorang adalah faktor internal dan ekternal tubuh seperti hasil penelitian yang dilakukan Sabatini, Nugraha, dan Dewi (2019) yang menyatakan bahwa faktor yang mempengaruhi daya ledak, meliputi: metode latihan dan latihan dengan target fisik. Daya ledak juga dipengaruhi oleh sistem syaraf dan sistem otot pemain itu sendiri (Stojanovic, Jovanovic, \& Stojanovic, 2012). Sistem syaraf merupakan bagian yang terpenting dalam menjalankan grup sistem otot yang berada pada tungkai atau daerah yang akan berkerja. Faktor yang juga berperan penting dalam peningkatan daya ledak adalah kekuatan anaerobik (Adibpour et al., 2012). Hal ini didasarkan bahwa daya ledak memerlukan waktu yang singkat untuk berkontraksi dan sesuai dengan ciri-ciri dari sistem energi anaerobik yang bekerja pada jangka waktu yang singkat.

Latihan plyometric bisa meningatkan kecepatan pergerakan otot yang dijalankan oleh sistem syaraf sehingga menyebabkan lebih cepatnya transisi dari kontraksi eksentrik ke kosentrik (Arazi \& Asadi, 2011). Akan tetapi latihan plyometric juga mempunyai resiko cedera yang bisa disebabkan oleh gaya luar yang terlalu besar yang terjadi pada persendian, tulang, otot, ligamen dan tendon (Arazi \& Asadi, 2011). Hal ini bisa menghambat perkembangan atlet itu sendiri.

Latihan plyometric sebaiknya dilakukan oleh pemain yang sudah pada tahap dewasa dan komposisi tulang sudah sangat keras. Jika latihan plyometric diberikan anak-anak harus dibantu dengan landasan yang tidak keras karena komposisi tulang anak-anak 
yang cenderung masih rawan dan masih dalam tahap perkembangan. Hal lain yang perlu diperhatikan dalam penyusunan program latihan harus berdasarkan prinsip individual karena karakter dan kemampuan otot setiap orang berbeda-beda (Pembayun, Wiriawan, \& Setijono, 2018). Berdasarkan hasil temuan dari (Attene et al., 2014; Ramirez-Campillo et al., 2014, 2015) mengungkapkan bahwa intervensi pelatihan plyometrik jangka pendek (6 minggu) hanya memberikan efek pelatihan kecil pada kinerja lompat pada atlet, khususnya wanita. Sedangkan Stojanovic, Ristic, McMaster, dan Mlanovic (2016) menyatakan bahwa manfaat pelatihan plyometrik pada kinerja vertical jump lebih besar untuk intervensi dengan durasi lebih lama yaitu lebih dari 10 minggu.

Pelatih harus bisa menerapkan program latihan yang sesuai dengan kebutuhan pemain di lapangan. Latihan plyometric bisa dikombinasikan dengan bentuk latihan lainnya agar daya ledak pemain semakin baik. Selain pelatihan plyometrics single leg jump dan depth jump ada pelatihan yang serupa dalam peningkatan tinggi lompatan yaitu plyometrics barrier hops yang sudah teruji dan berpengaruh signifikan terhadap tinggi lompatan pada pemain bola basket (Pembayun et al., 2018). Sedangkan Priambada (2015) mengatakan dalam penelitiannya bahwa pelatihan plyometrics depth jump juga bagus dalam meningkatkan power otot tungkai pada pemain bulutangkis. Pentingnya peran seorang pelatih dalam memberikan suatu model pelatihan yang tepat bagi kebutuhan seorang atlet untuk meningkatkan keterampilannya (Annuri, 2014).

\section{KESIMPULAN}

Hasil penelitian ini dapat disimpulkan bahwa terdapat pengaruh dan peningkatan yang signifikan antara latihan plyometric single leg jump terhadap daya ledak otot tungkai dan latihan plyometric depth jump kemampuan power dan under shoot pemain bola basket. Hal ini terlihat dari hasil post-test yang lebih besar dari pada hasil pre-test dari kelompok I maupun kelompok II, Jika dibandingkan dengan kelompok kontrol hasil post-test dan pre-test menunjukkan pada power dan pada under shoot memiliki peningkatan. Disarankan untuk pelatih untuk membuat program latihan plyometric agar kemampuan lompatan pemain bisa menjadi lebih baik.

\section{DAFTAR PUSTAKA}

Adibpour, N., Bakht, H. N., \& Behpour, N. (2012). Comparison of the Effect of Plyometric and Weight Training Programs on Vertical Jumps in Female Basketball Players. World Journal of Sport Sciences, 7(2), 99-104. https://doi.org/10.5829/idosi.wjss.2012.7.2.1173

Annuri, U. (2014). Hubungan Daya Ledak Otot Tungkai dan Otot Lengan Dengan Kemampuan Shooting Atlet Bola Basket. Universitas Negeri Yogyakarta.

Arazi, H., \& Asadi, A. (2011). The effect of aquatic and land plyometric training on strength, sprint, and balance in young basketball players. Journal of Human Sport and Exercise, 6(1), 101-111. https://doi.org/10.4100/jhse.2011.61.12

Asadi, A. (2013). Effects of in-season short-term plyometric training on jumping and agility performance of basketball players. Sport Sci Health, 9, 133-137. https://doi.org/10.1007/s11332-013-0159-4 
Attene, G., Iuliano, E., Cagno, A, D., Calgagno, G., Moalla, W., Aquino, G., \& Padulo, J. (2014). Improving neuromuscular performance in young basketball players: plyometric vs. technique training. Journal of Sports Medicine Phys Fitness, 55(1), 1-8.

Bal, B. S., Kaur, P. J., \& Singh, D. (2011). Effects of A Short Term Plyometric Training Program of Agility in Young Basketball Players. Brazilian Journal of Biomotricity, 5(4), 271-278.

Chu, D. A., \& Meyer, G. C. (2013). Plyometrics. Champaign, IL: Human Kinetics.

Hidayat, T., Saichhudin, \& Kinanti, R. G. (2017). Pengaruh latihan plyometric depth jump dan jump to box terhadap power otot tungkai pada pemain ekstrakurikuler bolavoli SMK Teknologi Nasional Malang. Jurnal Sport Science, 7(2), 1-8.

Jaya, I. P. P., Tirtayasa, K., Muliarta, I. M., Adiputra, L. M. I. S. H., Purnawati, S., \& Griadhi, I. P. A. (2018). Pelatihan Pliometrik Depth Jump Lebih Meningkatkan Daya Ledak Otot Tungkai Daripada Pelatihan Pliometrik Box Jump Siswa Peserta Ekstrakurikuler Bola Voli SMK Negeri 1 Petang. Sport and Fitness Journal, 6(3), 8-18. https://doi.org/https://doi.org/10.24843/spj.2018.v06.i03.p02

Maksum, A. (2012). Metodologi Penelitian. Surabaya: Unesa University Press.

Nurhasan. (2000). Tes dan Pengukuran Pendidikan Olahraga. Bandung: Universitas Pendidikan Indonesia.

Pembayun, D. L., Wiriawan, O., \& Setijono, H. (2018). Pengaruh Latihan Jump To Box, Depth Jump dan Single Leg Depth Jump Terhadap Peningkatan Kekuatan Otot Tungkai dan Power Otot Tungkai. Jurnal SPORTIF: Jurnal Penelitian Pembelajaran, 4(1), 87-104. https://doi.org/https://doi.org/10.29407/js_unpgri.v4i1.12006

Priambada, T. A. (2015). Pengaruh Latihan Pliometrik Depth Jump Terhadap Power Otot Tungkai Pada Pemain Bulutangkis UMS. Universitas Muhammadiyah Surakarta.

Rajan, S., \& Pushparajan. (2010). Effects of Plyometric Training on The Development The Vertical Jump in Volleyball Players. JPES Journal of Physical Education and Sport, 28(3), 65-69.

Ramirez-Campillo, R., Alvarez, C., Henriquez-Olguin, C., Baez, E. B., Martinez, C., Andrade, D. C., \& Izquierdo, M. (2014). Effects of plyometric training on endurance and explosive strength performance in competitive middle-and long-distance runners. Journal of Strength and Conditioning Research, 28(1), 97-104.

Ramirez-Campillo, R., Gonzalez-Jurado, J. A., Martinez, C., Nakamura, F. Y., Penailillo, L., Meylan, C. M. P., ... Izquierdo, M. (2015). Effects of plyometric training and creatine supplementation on maximal-intensity exercise and endurance in female soccer players Rodrigo. Journal of Science and Medicine in Sport, 19(8), 682-687. https://doi.org/10.1016/j.jsams.2015.10.005

Sabatini, N. K. G., Nugraha, M. H. S., \& Dewi, A. A. N. T. N. (2019). Faktor-faktor yang mempengaruhi kecepatan, kekuatan, dan daya ledak terhadap tendangan pada atlet taekwondo. Jurnal Pendidikan Olahraga, 8(2), 85-95. https://doi.org/10.31571/jpo.v8i2.1120 
Stojanovic, E., Ristic, V., McMaster, D. T., \& Mlanovic, Z. (2016). Effect of Plyometric Training on Vertical Jump Performance in Female Athletes: A Systematic Review and Meta-Analysis. Sports Med, 49, 975-986. https://doi.org/10.1007/s40279-016-0634-6

Stojanovic, N., Jovanovic, N., \& Stojanovic, T. (2012). The effects of plyometric training on the development of the jumping frequency of volleyball players. Physical Education and Sport, 10(1), 59-73.

Wanena, T. (2018). Kontribusi power otot tungkai, kekuatan otot lengan, dan koordinasi mata tangan dengan kemampuan jump shot bolabasket pada mahasiswa FIK Uncen Tahun 2017. JPOS (Journal Power Of Sports), 1(2), 8-13. 